\title{
UPPER OCEAN STRATIFICATION IN THE BAY OF BENGAL
}

\author{
Eric A. D’Asaro \\ APL/UW 1013 NE 40 ${ }^{\text {th }}$ Str, Seattle, WA 98105 \\ phone: (206) 685-2982 fax: (206) 543-6785 email: dasaro@apl.washington.edu
}

Award Number: N00014-13-1-0504, N00014-14-1-0235, N00014-10-1-0313

http://apl.uw.edu/dasaro

\section{LONG-TERM GOALS}

In collaboration with Indian oceanographers, we seek to measure and understand the processes controlling the stratification of the upper 100m of the Bay of Bengal and to educate a new generation of young Indian oceanographers in the methods used.

\section{OBJECTIVES}

Upper ocean physics plays a key role in controlling the intensity and timing of the Northern Indian Ocean monsoons, with the ocean and atmosphere representing a strongly coupled air-sea interaction system, which in turn plays an important role in climate variability at both regional and global scales. The ASIRI program, a Departmental Research Initiative of ONR's code 32, seeks to understand these interactions through measurement and modeling focused on the Bay of Bengal. Existing coupled ocean-atmosphere models in this region show little skill in predicting the summer monsoon, particularly its IntraSeasonal Oscillations (ISO). One possible cause is a poor simulation of the air-sea interaction processes. The northern Bay of Bengal has strong ISO fluctuations in SST, which lead the monsoonal fluctuations by about a week, thereby suggesting a causal relationship between monsoon ISO variations and ocean dynamics. However, most existing models predict surface temperatures that are too cold and mixed layer depths that are too deep. The biases are large and likely reduce the intensity of air-sea interaction by overestimating the thermal inertia of the upper ocean and thus the time scale on which the ocean can respond to the atmosphere. A likely reason for this bias is an improper representation of the role of freshwater input, both from rain and from the enormous river inflow into the northern Bay of Bengal. Specific goals for this grant are:

- Measure the salinity and temperature stratification of the upper $100 \mathrm{~m}$ with a particular emphasis on the upper 10m and mixed layer, if any, throughout the annual cycle including the summer monsoon and the ocean response to it and recovery from it.

- Understand the relative importance of vertical processes, as represented by wind, flux and wave driven boundary layer models, internal wave mixing, and lateral processes, as represented by submesoscale-resolving process models, in setting the stratification and upper ocean circulation.

\section{APPROACH}

Since the early 1990s, ONR has supported the development and use of "Lagrangian Floats" designed, built and operated at the Applied Physics Laboratory, University of Washington. 


\section{Report Documentation Page}

Form Approved OMB No. 0704-0188

Public reporting burden for the collection of information is estimated to average 1 hour per response, including the time for reviewing instructions, searching existing data sources, gathering and maintaining the data needed, and completing and reviewing the collection of information. Send comments regarding this burden estimate or any other aspect of this collection of information,

including suggestions for reducing this burden, to Washington Headquarters Services, Directorate for Information Operations and Reports, 1215 Jefferson Davis Highway, Suite 1204, Arlington

VA 22202-4302. Respondents should be aware that notwithstanding any other provision of law, no person shall be subject to a penalty for failing to comply with a collection of information if it

does not display a currently valid OMB control number.

\begin{tabular}{|c|c|}
\hline $\begin{array}{l}\text { 1. REPORT DATE } \\
\mathbf{2 0} \text { SEP } \mathbf{2 0 1 4}\end{array}$ & 3. DATES COVERED \\
\hline \multirow{3}{*}{$\begin{array}{l}\text { 4. TITLE AND SUBTITLE } \\
\text { Upper Ocean Stratification in the Bay of Bengal }\end{array}$} & 5a. CONTRACT NUMBER \\
\hline & 5b. GRANT NUMBER \\
\hline & 5c. PROGRAM ELEMENT NUMBER \\
\hline \multirow[t]{3}{*}{ 6. AUTHOR(S) } & 5d. PROJECT NUMBER \\
\hline & 5e. TASK NUMBER \\
\hline & 5f. WORK UNIT NUMBER \\
\hline $\begin{array}{l}\text { 7. PERFORMING ORGANIZATION NAME(S) AND ADDRESS(ES) } \\
\text { APL/UW,,1013 NE 40th Str,,Seattle,,WA,98105 }\end{array}$ & $\begin{array}{l}\text { 8. PERFORMING ORGANIZATION } \\
\text { REPORT NUMBER }\end{array}$ \\
\hline \multirow[t]{2}{*}{ 9. SPONSORING/MONITORING AGENCY NAME(S) AND ADDRESS(ES) } & 10. SPONSOR/MONITOR'S ACRONYM(S) \\
\hline & $\begin{array}{l}\text { 11. SPONSOR/MONITOR'S REPORT } \\
\text { NUMBER(S) }\end{array}$ \\
\hline
\end{tabular}

12. DISTRIBUTION/AVAILABILITY STATEMENT

Approved for public release; distribution unlimited.

13. SUPPLEMENTARY NOTES

The original document contains color images.

14. ABSTRACT

15. SUBJECT TERMS

16. SECURITY CLASSIFICATION OF:

a. REPORT unclassified b. ABSTRACT unclassified c. THIS PAGE unclassified
17. LIMITATION OF ABSTRACT

\begin{tabular}{c|l}
$\begin{array}{c}\text { 18. NUMBER } \\
\text { OF PAGES }\end{array}$ & 19a. NAME OF \\
$\mathbf{7}$ & RESPONSIBLE PERSON \\
&
\end{tabular}


These are robust platforms for studying upper ocean processes, capable of carrying a wide variety of sensor suites (we have integrated about 30 different sensors) and particularly designed to accurately track water parcels in three-dimensions. They are fully autonomous using Iridium communications for control and data transfer.

A particular challenge for all buoyancy driven vehicles (floats and gliders) in the Bay of Bengal is the presence of very fresh, low density water near the surface, which can prevent such vehicles from profiling all the way to the surface and/or lifting their satellite antennas far enough out of the water to communicate. Salinities as low as

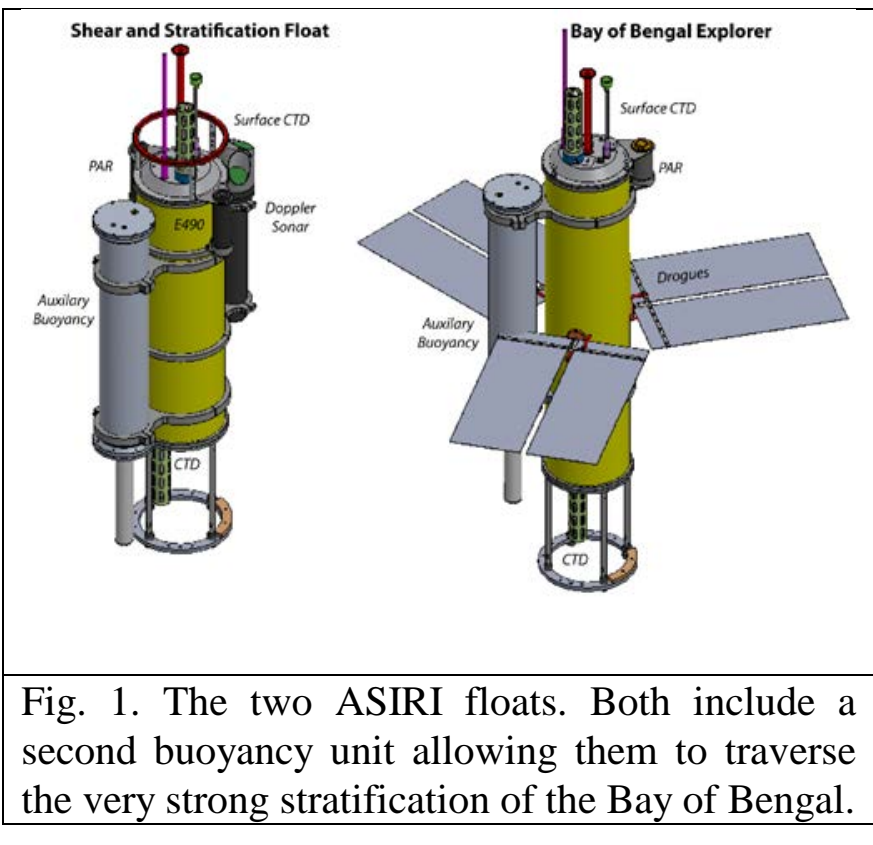
$21 \mathrm{psu}$, can occur here during and after the summer monsoon. Spanning the density range between this and the $100 \mathrm{~m}$ depth, would require nearly all ( 550cc) of the available (650cc) buoyancy control of a standard Lagrangian float.

Two Lagrangian floats are currently under construction for this work with specialized sensors for the Bay of Bengal. The Shear and Stratification Float (SSF) is designed to be deployed from a ship and measure the near-surface shear and stratification in detail. The Bay of Bengal Explorer (BBE) is designed for long-term (6+ months) operation, measuring stratification and turbulence. Systems on these floats are:

- 2 standard SBE-41CT ctd's, on the top and bottom of the float, measure salinity and temperature. Two sensors are needed given the strong density gradients to properly ballast the float and for redundancy since these are crucial sensors for float operation.

- A special Seabird 'Surface CTD' designed to rapidly profile the near-surface salinity as the float penetrates the surface on an upward profile. These sensors will provide very high vertical resolution near the surface where the Bay of Bengal stratification is very strong.

- Light sensors, designed to measure light level as a function of depth and thus the optical clarity of the water. This is crucial for determining the heating of the upper layer. The BBE has PAR sensor equipped with a window-wiper that actively removes fouling of the optical window. In previous deployments, we have found this to be very effective. The SSF has both a PAR and a $490 \mathrm{~nm}$ sensor in order to provide a more detailed view of the light field.

- A new auxiliary buoyancy module attached to the side of the float. This doubles the buoyancy control of the float by duplicating the current internal buoyancy system and thus allows the float to easily overcome the large salinity variations in the Bay of Bengal.

- The usual pressure sensors, Iridium communications, ARGOS backup system and software controlling a customized ASIRI float mission. The typical mission will alternate profiles to the surface with extended drifts of the float within the surface boundary layer to measure the turbulence levels and surface waves.

\section{WORK COMPLETED}

Eric D'Asaro and Michael Ohmart (the technician who builds the floats) participated in two cruises on the R.V. Sagar Nidhi, in November/December 2013 and August/September 2014, as 
the sole U.S. ASIRI participants in these cruises. This was done in collaboration with Drs. Debasis Sengupta, G. S. Bhat (COAS, Bangalore) and M. Ravichandran (INCOIS, Hyderabad). We assisted our partners in installing and operating an underway CTD and over-the-side ADCP on the ship and worked with them and their students to design the experimental strategy. In addition, Eric D’Asaro gave several lectures during the cruises and Mike Ohmart worked with all of the experimental teams to help refine their shipboard procedures.

Eric D’Asaro was also a teacher at the ASIRI-OMM summer workshop on Upper Ocean Physics in the Bay of Bengal at IISc Bangalore July 8-21, 2014. He gave five lectures and worked with the students on their mini-projects.

\section{RESULTS}

November/December 2014 Sagar Nidhi cruise- To quote the cruise report written by Drs. Sengupta and Ravichandran: "During the Ocean Mixing and Monsoon (OMM)-Air-Sea Interaction Research Initiative (ASIRI) cruise to the Bay of Bengal in November 2013, the Indian

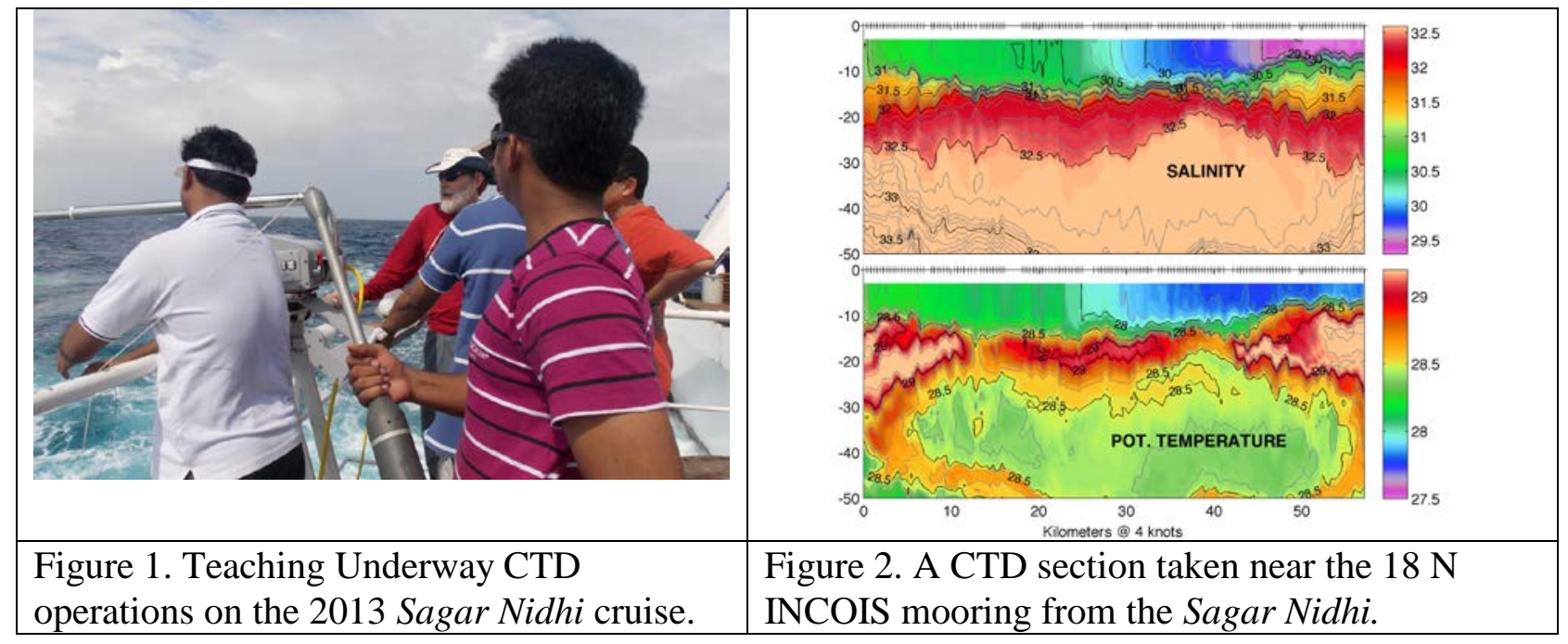

research ship Sagar Nidhi (Cruise SN82) worked with the US ship Roger Revelle to study lateral and vertical gradients of temperature, salinity and density in the upper ocean. The Sagar Nidhi obtained somewhat limited but very useful observations. The onboard training of Indian personnel was an unqualified success, thanks mainly to the close interaction of experienced scientists, including Eric D’Asaro and Michael Ohmart (Applied Physics Laboratory, University of Washington,) with young engineers and students from several universities and institutes.”

This cruise also taught us about how to operate in India. The two floats did not arrive in time for the cruise, due to shipping and customs difficulties. In retrospect, this allowed us to concentrate on the more important tasks of training and collaboration. Scientifically, we obtained a few km-resolution CTD sections (Fig. 2) in the northern Bay of Bengal. They show large variations in salinity (1.5 psu in Fig. 2), very strong vertical stratification (2.5 psu in 10m) and shallow mixed layers (3-10m).

July 2014 Summer Workshop- The ASIRI-OMM summer workshop at IISc Bangalore was attended by 18 early career scientists (included four women) from IISc, INCOIS, NIOT, SACAhmedabad, IIT Madras, IIT Bhubaneswar and TIFR Hyderabad. The workshop consisted of two 90-minute lectures in the morning and workshop/mini-projects in the afternoon. The students explored their mini-projects way into evenings and weekends, with several groups reporting that they worked on their projects overnight as the presentation day grew closer. The 


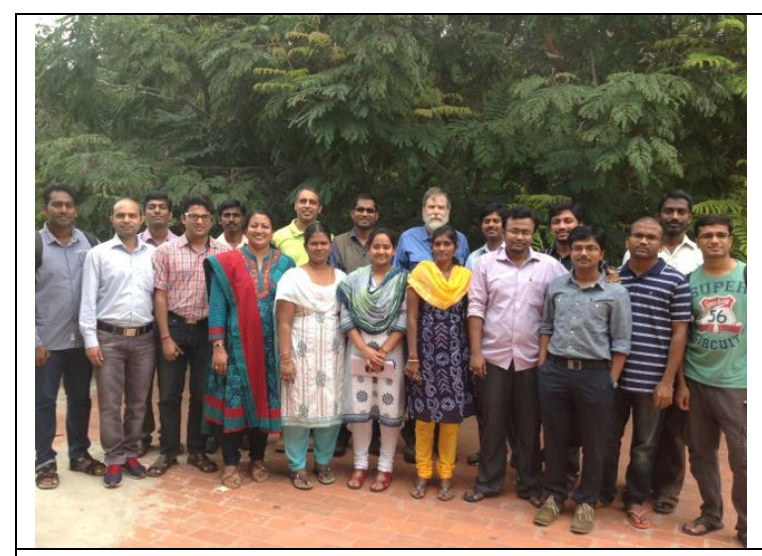

Figure 3. 2014 OMM/ASIRI summer workshop participants. student groups presented their mini-projects on the last day on July 21st, and each student from the group participated in the presentation of their project. An anonymous feedback survey asked students what went well, what they would like to see improved and suggestions for future topics. The survey elicited very positive responses on the demonstrations and the teaching: "The theory we learned in notebooks, we saw it for the first time visually", "teaching was excellent by the respective professors", "demos were excellent”, "workshop is excellent in every way, really it created enthu(iasm) inside us”, “please keep coming to CAOS", "the energy level as well as the teaching skills of the professors who handled each subject made the toughest parts of oceanography to a very lighter level.

For the US teachers, the workshop gave us further opportunity to understand the Indian oceanographic community, to work with its future leaders and to plan upcoming fieldwork.

August/September 2014 Sagar Nidhi cruise- To again quote the Indian cruise report: “The ship sailed from Chennai on the evening of 22nd August, 2014 ... and returned back to Chennai on 09th September, 2014. Our main objective on this cruise was to observe upper ocean submesoscale (1-10 km) variability in monsoon conditions. We were particularly interested in identifying and characterizing sharp lateral salinity gradients of salinity (fronts); the influence of salinity fronts on near-surface stratification and horizontal currents; and the relation between the stratification and penetration of momentum from wind stress. In addition, we deployed instruments to study upper ocean optics, chemistry and biology; velocity and temperature microstructure; atmospheric radiation and aerosols, surface fluxes from shipboard sensors, and profiles of atmospheric temperature, humidity and winds. Prof. Eric D’Asaro and Michael Ohmart, our collaborators from the Applied Physics laboratory, University of Washington, deployed a water-following Lagrangian float to study upper ocean stratification, velocity shear and turbulence.

A total of 22 people from ...[multiple]... institutions participated in this OMM cruise. ... Real-time remote sensing and model-based products for the Bay of Bengal were provided by ... the Indian Space Research Organisation (ISRO) ... and by Mr. Jared M. Buckley and Prof. Amit Tandon of the University of Massachusetts Dartmouth (UMassD). ... The satellite and model inputs proved very useful in cruise planning as well as day to day science decisions made on the ship."

The success of this cruise was a direct result of the training conducted on the 2013 cruise and the participation of young Indian scientists in the 2013 and 2014 Roger Revelle cruises. Underway CTD data was taken nearly continuously on the cruise with little input from the U.S. team. The ADCP, which was useless in the 2013 cruise, returned excellent data. These technical successes allowed us to focus on our scientific goals.

Mesoscale CTD/ADCP surveys shows structure similar to those in Fig. 2, but with surface salinities as low as 28 psu. By refining these surveys to increasing small scale, a kmscale front was found and the SSF float deployed within it. The float deployment was cut short by a failure of the secondary ballasting system, which prevented us from obtaining real-time GPS fixes of the float position, thus preventing the planned coordinated ship-float operations. However, we retained the ability to communicate with the float and were thus able to obtain good data and recover the float. The failure was traced to a manufacturing defect in a hardened steel 


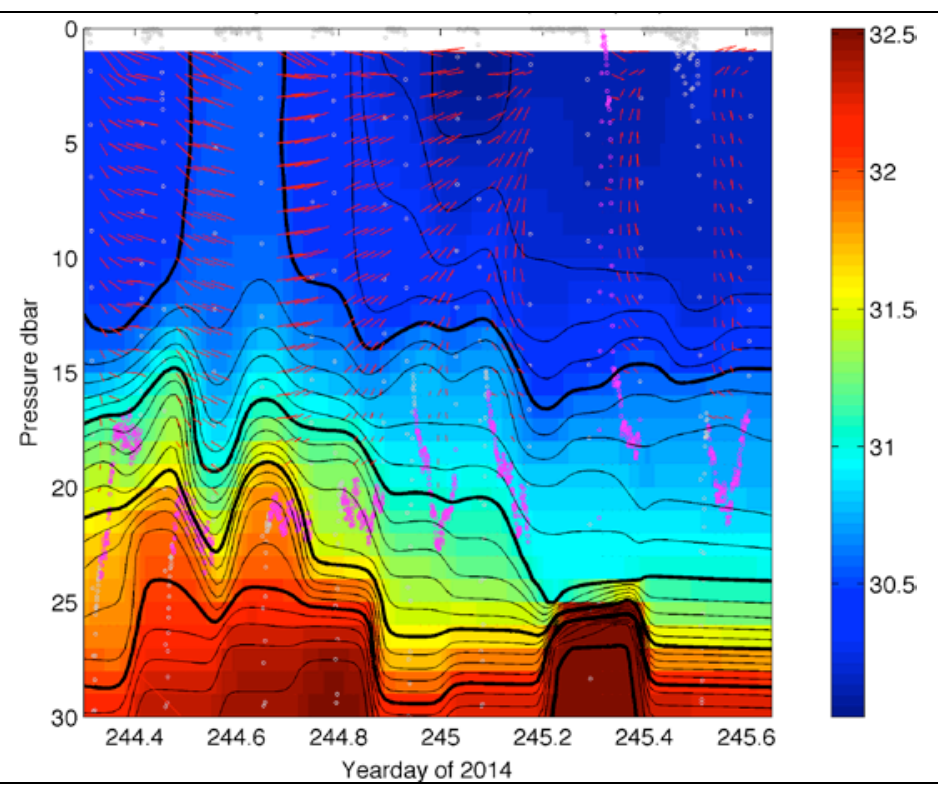

Figure 4. Data from the Lagrangian float deployment. Dots show float data locations; contours and colors show interpolated salinity; vectors (red) show velocities relative to the float.

bolt. We anticipate that additional testing will allow us to prevent this failure in future deployments. All other float systems and sensors operated well.

Fig. 4 shows shear and stratification data from the float deployment. The float travelled across the 0.5 psu front (colors) with the mixed layer varying from less than $2 \mathrm{~m}$ deep near yearday 245.1 to a more typical $10 \mathrm{~m}$. Velocities measured relative to the float (red arrows) during its drifts at $20 \mathrm{~m}$ (magenta dots) show an approximately $0.1 \mathrm{~m} \mathrm{~s}^{-1}$ inertial oscillation, rotating clockwise with time and with a strong shear across the halocline. These are the first ADCP measurements made from a Lagrangian float; their structure is entirely reasonable. Comparison of the vertical velocity measured by the ADCP and the actual vertical motion of the float confirm that the ADCP was working well.

\section{RELATED PROJECTS}

The ADCP/float measurements pioneered here are expected to play an important role in upcoming measurements as part of the Waves, Langmuir Cells and the Upper Ocean Boundary Layer Departmental Research Initiative

\section{PUBLICATIONS}

Lucas, A. J., et. al (2014), Mixing to Monsoons: Air-Sea Interactions in the Bay of Bengal, Eos Trans. AGU, 95(30), 269

\section{HONORS/AWARDS/PRIZES}

Eric D’Asaro was elected to the National Academy of Sciences, the first experimental physical oceanographer so honored in many years. This undoubtedly reflects scientific contributions made possible by ONR support over the last 30 years. 


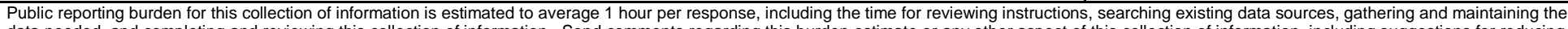

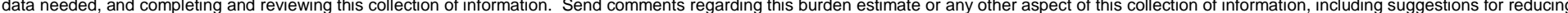

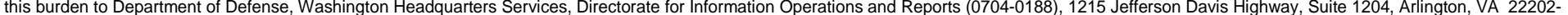

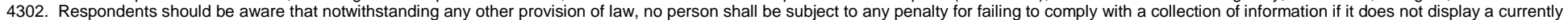
valid OMB control number. PLEASE DO NOT RETURN YOUR FORM TO THE ABOVE ADDRESS.

\begin{tabular}{l|l|l} 
1. REPORT DATE (DD-MM-YYYY) & 2. REPORT TYPE & 3. DATES COVERED (FrOm - TO)
\end{tabular}

20/09/2014 $\quad$ Final Technical

4. TITLE AND SUBTITLE

Upper Ocean Stratification in the Bay of Bengal

Bay of Bengal Boundary Layer Measurements for ASIRI Pilot

$01-04-2013$ to $31-03-2014$

5a. CONTRACT NUMBER

5b. GRANT NUMBER

N00014-13-1-0504

5c. PROGRAM ELEMENT NUMBER

6. AUTHOR(S)

Eric D’Asaro

5d. PROJECT NUMBER

5e. TASK NUMBER

5f. WORK UNIT NUMBER

7. PERFORMING ORGANIZATION NAME(S) AND ADDRESS(ES)

University of Washington - Applied Physics Laboratory

8. PERFORMING ORGANIZATION REPORT

4333 Brooklyn Avenue NE NUMBER

Seattle, WA 98105-6613

9. SPONSORING I MONITORING AGENCY NAME(S) AND ADDRESS(ES)

Office of Naval Research

10. SPONSOR/MONITOR'S ACRONYM(S)

ONR

ONR BDCC

One Liberty Center

875 North Randolph Street, Suite 1425

11. SPONSOR/MONITOR'S REPORT NUMBER(S)

Arlington, VA 22203-1995

12. DISTRIBUTION / AVAILABILITY STATEMENT

Distribution Statement A: Approved for public release; distribution is unlimited.

13. SUPPLEMENTARY NOTES

This report also serves as the interim report for ONR grant N00014-14-1-0235.

\section{ABSTRACT}

In collaboration with Indian oceanographers, we sought to measure and understand the processes controlling the stratification of the upper $100 \mathrm{~m}$ of the Bay of Bengal and to educate a new generation of young Indian oceanographers in the methods used.

15. SUBJECT TERMS

16. SECURITY CLASSIFICATION OF:

a. REPORT

Unclassified b. ABSTRACT

Unclassified c. THIS PAGE

Unclassified
17. LIMITATION OF ABSTRACT

UU
18. NUMBER OF PAGES

6 19a. NAME OF RESPONSIBLE PERSON

Eric D'Asaro

19b. TELEPHONE NUMBER (include area code) (206) 685-2982 